\title{
Introduction of Computer Aided Test Analysis Program for Civil Engineering
}

\author{
Zheng $\mathrm{Wu}^{1}$, Yang Lee ${ }^{2}$, Chong Lee ${ }^{3}$ \\ ${ }^{1}$ PowerChina Chengdu Engineering Corporation Limited, ECC, Chengdu, 610072, China \\ ${ }^{2}$ Kylin software co., Ltd., Tianjin, 30045, China \\ ${ }^{3}$ North China Municipal Engineering Design \& Research Institute Co., Ltd Chongqing Branch, Chongqing, 401147, \\ China
}

\begin{abstract}
The Computer Aided Test Analysis for Civil Engineering (CATACE) is made based on international standards, regulations and specifications. It includes test analysis for aggregates, bitumen, soil, asphalt concrete and its mixtures. It includes the technical requirements for nuclear gauge, selection parameter for surface dressing, blending for prime coat and tack coat. It provides the unit conversion between American to international system. It provided over 40 kinds of test analysis, and it will be increase working efficiency for the Material Testing Engineer who is working oversea project and follows international standards. The paper introduces the functions and application of the program.
\end{abstract}

Keywords: civil engineering; laboratory test; computer aided test analysis

\section{The Basic Characteristics of the Program}

The Computer Program of CATACE is written in Visual Basic, it can be used under any Windows System, the main characteristics of the program are those as follows:

(1) There is an engineering practice example for each test analysis. When user change the test data and click the mouse, the new result will be generated automatically.

(2) Computational accuracy will be adjusted automatically according to type of the test as per the test specifications or standards.

(3) It provides 23 kinds of Unit conversion; it can be used to change from American unit to international unit and vice versa. It provides benefit for user to read technical documents other than international unit from other countries.

(4) It provides test specification which can be easily to source out for further study and analysis for the test report.

(5) The background color is green for input box and yellow color for output box; Italics letter is used for the description of to be calculated content and the output results so that to reduce the eyestrain of the user.

(6) The modular design idea is used in written of the program so that the program is an easily to be maintained and to be upgraded.

(7) It provides the comprehensive data analysis platform, it can be used each kinds of test data and find the related test information, and it provide the much of working efficiency for the user.

(8) The program is easy to use and easy to learn. 
(9) The program can be used for laboratory test analysis for civil works, it can be used for construction quality control, it will be especially helpful for those engineer who is the first time to work overseas.

\section{The Function of the Program}

\subsection{Aggregate test}

2.1.1 Durability index test

Aggregate durability test is based on ASTM D 3744-94 and AASHTO T 210-95, this test method is used in several states in USA. It is reported that this test method may replace the time consuming method of Sodium Sulfate Soundness (SSS) test.

\subsubsection{Aggregate impact value test}

Aggregate impact value is used to review of the Impact behavior of the aggregate, the test method is BS 812 Part 112: 1990. The standard size of aggregate for the test is $14 / 10 \mathrm{~mm}$, but it also can be used for the aggregate with size under $10 \mathrm{~mm}$.

\subsubsection{Aggregate soundness test}

Aggregate soundness test is used to review durability and weathering resistance of aggregates. The Program is made as per the standard of AASHTO T 104-97 and S 812: Part 121: 1989. The Program provides example to preparation of solution for Sodium Sulfate Soundness (SSS) and determination of aggregate specific gravity for SSS test.

\subsubsection{Aggregate shape test}

The aggregate shape test is based on British standard, the flaky index test is based on standard of BS 812 Section 105.2: 1990, the elongation index test is based on standard of BS 812 Section 105.1: 1990. They are used for test aggregate with size of $6.3 \mathrm{~mm}$ to $50 \mathrm{~mm}$ 。

\subsubsection{Specific gravity test}

The Program is made as per the test standard of ASSTHO T85-96 and T84-95. it could be used for analysis of specific gravity of fine and course aggregates. The program automatically calculate bulk specific density in oven-dry condition, bull specific gravity in SSD condition, apparent specific density and absorption of the aggregates.

\subsubsection{ACV}

Aggregate Crushing Value (ACV) is used for review of aggregate behavior under compression loading. The test is simple, quick, easy operation and has a good repeatability. The size of aggregate to be used for the test is $14 / 10 \mathrm{~mm}$, the loading is $400 \mathrm{kN}$. The standard of BS812 is used for the test analysis.

\subsubsection{0\% Fine value}

$10 \%$ Fine value is loading under $10 \% \mathrm{ACV}$, which is used to review of compressive behavior of aggregate.

\subsubsection{Unit weight}

Unit weight test is used for calculation of air voids of fine and coarse aggregates, this is a basic test for cement concrete mix proportion design, and it suitable for aggregate with particle size under $150 \mathrm{~mm}$. the test method used in the program is AASHTO T19/ T 19M-97 and ASTM C29/ C29M-91A。

\subsubsection{Friable particles}

As per AASHTO T112-96 and ASTM C142-90 test method, the program can be used for calculation of friable particles inside the aggregates.

\subsubsection{LAA}

Los Angles Abrasive (LAA) test is used for review of aggregate behavior under impaction, friction and abrasion which is suitable for aggregate under $37.5 \mathrm{~mm}$. The test specification of AASHTO T96-94 and ASTM C131-89 is used for 
the analysis.

\subsubsection{Fine modulus}

The method of Fine Modulus (FM) calculation followed is AASHTO T27-97, the maximum size of the aggregate is $37.5 \mathrm{~mm}$. It is noticed that the method is different with Chinese Test Standard but the calculation result is same for them.

\subsubsection{Gradation test}

The program can be used for grading test analysis for aggregates of asphalt concrete, base, subbase of the road works. The grading curve can be generated automatically, so that it can be used for the quality control of grading test to check them in smooth curve or not, within the specified limit or not, the grading needs to be adjusted or not.

\subsubsection{Shape and texture index test}

The test method is ASTM D 3398-97 which to determine the shape and texture index, the program will calculate the weighted particle index automatically, some detail requirement to prepare the sample can be found in the program.

\subsection{Bitumen test}

\subsubsection{Specific gravity test}

AASHTO T 228-94 and ASTM D 70-82 test specification is adopted in the program.

\subsubsection{Distillation test}

The computer Program will do the calculation of the weight of bitumen to the base temperature at $15.6^{\circ} \mathrm{C}$ for bitumen under any temperature and in volume of $200 \mathrm{ml}$ so that user can use the value for carrying out distillation test. When the value of distillation test is done, the program will do the calculation of distilled value of bitumen as per standard of AASHTO T78-96 and ASTM D4311-96.

\subsubsection{Penetration index}

When input penetration value under 5 different temperature, the program can be used to calculate bitumen modified soft point, modified bitumen index (PI), range of plastic temperature. When penetration at $25^{\circ} \mathrm{C}$ is input, the program will calculate the softening point so that to understand bitumen temperature susceptible.

\subsubsection{Penetration viscosity number}

When input bitumen penetration value $(0.1 \mathrm{~mm})$ at $25^{\circ} \mathrm{C}$ and bitumen kinematic viscosity at $135^{\circ} \mathrm{C}(\mathrm{cm} 2 / \mathrm{s})$, or input bitumen penetration value $25^{\circ} \mathrm{C}$ and absolute viscosity at $60^{\circ} \mathrm{C}$ (Pa.s), the computer Program will calculate penetration viscosity number so that bitumen susceptible to temperature can be determined.

\subsubsection{Cup viscometer test}

The viscosity shall be determined for cut-back bitumen and emulsified bitumen. The kinematic viscosity of emulsified -bitumen can be determined by using standard viscosity meter. The Program provides 7 different kinds of viscometer, when input the test data, the viscosity will be calculated automatically.

\subsubsection{Viscosity conversion}

The program provides conversion for 7 different viscosities, when one type viscosity is known; the program can tell us other 6 type of viscosity.

\subsubsection{Bitumen blending}

Two-different penetrated bitumen can be combined into required penetrated bitumen or two-different softening point bitumen can be combined into one required softening point. The program can be used for calculation of such blending purpose; it will carry out the design as per the requirement of user which benefit for the bituminous work.

\subsubsection{Bitumen volume conversion}

Some technical specification specifies that the volume of bitumen spraying rate shall be determined at base 
temperature of $15^{\circ} \mathrm{C}$ or $15.6^{\circ} \mathrm{C}$. ASTM D 4311-96 provides volume conversion coefficient for cut-back bitumen and penetrated bitumen at any temperature, while ASTM D633-97provide the same for the tar.

The program can be used for the calculation bitumen volume at base temperature for any kind of bitumen at any temperature.

\subsubsection{Prime and tack coat}

The program can be used for calculation in making both of prime coat and tack coat by using penetrated bitumen plus kerosene; also it can be used for conversion calculation between tack coat and prime coat which provide great assistant in bituminous work or asphalt concrete works.

\subsubsection{Spraying temperature}

The program provides different bitumen spraying temperature under different spray jets and slot jets which can be used for the quality control in prime coat and tack coat.

\subsubsection{Selection of cut-back bitumen and emulsified bitumen}

The program can be used for quick selection of cut-back bitumen as per ASTM D3299-91 and quick selection of emulsified asphalt as per ASTM D3628-97.

\subsubsection{Bitumen property}

The program can be used to find the coefficient of bitumen cubical expansion, permittivity, frass braking pint, absolute viscosity, kinematic viscosity, adhesion in present of water, specific heat, thermal conductivity, electrical conductivity, dielectric strength, adhesion of bitumen and bitumen Poisson's ratio.

2.2.13 Flexual creep stiffness of asphalt binder using the bending beam rheometer

Flexural creep stiffness test for asphalt binder is carried out bending beam rhemeter, it is used for measuring stiffness of small beam specimen under creep loading to show the long term deformation behavior of bitumen. The program can be used of the test calculation and provide the related coefficient and regression coefficient.

\subsection{Soil test}

\subsubsection{Soil classification}

\subsubsection{Soil description}

As per ASTM D 2488-93, the description of angularity, particle shape, toughness, plasticity, dilatancy, moisture content, reaction with HCI with total terminology of 34 items can be found in the program.

\subsubsection{Soil classification of engineering purpose}

After input the value of sieve size for passing $60 \%, 30 \%$ and $10 \%$ on the cumulative distribution curve, also input the percentage passing sieve size of $4.75 \mathrm{~mm}, 0.075 \mathrm{~mm}$ as well PI and LL value, the program will do the calculation of coefficient of curvature $\mathrm{Cc}$, Coefficient of uniformity $\mathrm{Cu}$, and provide soil classification according to the engineering purpose as per ASTM D2487-98. The program is also providing the terminology of 14 items as per ASTM D2487-98.

\subsubsection{Soil classification in highway purpose}

When input the passing rate value on sieve size of $2.0 \mathrm{~mm}, 0.475 \mathrm{~mm}$ and $0.075 \mathrm{~mm}$ as well as PI and LL value the program will provide soil classification for highway construction purpose as per ASTM D3282-97 and AASHTO M145-95, the program will provide soil group classification, group index values automatically.

\subsubsection{Soil moisture content}

This is a basic and routine test.

\subsubsection{Specific gravity for soil}

As per ASTM D 854-92, the program can be used for data analysis for specific gravity for fine particle with size of 
$4.75 \mathrm{~mm}$ and under. When the temperature within $16^{\circ} \mathrm{C}$ to $30^{\circ} \mathrm{C}$, the program will do the temperature adjustment automatically and calculate the results at specified temperature of $20^{\circ} \mathrm{C}$.

\subsubsection{Soil shrinkage limit test}

The program will do the calculation for soil shrinkage limit test as per ASTM D 427-98 and ASTM D4943, which is suitable for particle size of $0.425 \mathrm{~mm}$ and under.

\subsubsection{Soil liquid limit test}

The program will do the calculation for soil Liquid Limit (LL) as per AASHTO T 89-96 and ASTM D 4318 which is called Casgrande method.

\subsubsection{Soil proctor compaction test}

Using the program, the user can find out the volume of mold, blows per layer, mass of rammer, drop depth, layers to be compacted as per AASHTO T 180-97, ASTM D1557-98 and BS standard. According to the data above, the program can be used to calculate the compaction effort. When there is oversize aggregate, the program can be used for correction coarse particles in the soil compaction test as per AASHTO T 224-96 and get the corrected Maximum Dry Density (MDD).

\subsubsection{Soil compaction density test}

Normally nuclear gauge method or sand replacement will be used for filed density test. The program can be used for data analysis for the method of Sand-Cone Method and Rubber-Balloon Method.

\subsubsection{CBR test}

The program provide details how to preparation of CBR test as per AASHTO T193-98 so that correct CBR test can be carried out.

\subsubsection{Soil bearing capacity test}

The program provides soil bearing capacity evaluation by DCP test and Filed Vane Shear test in cohesive soil as per AASHTO 223-96, the latter is used to determine the shear strength of cohesive soil with normal value of $20 \mathrm{kPa}$ below.

\subsubsection{Soil resilient modulus}

As per road design guidance of AASHTO, the program provides the soil resilient modulus prediction calculation.

\subsubsection{Construction parameter of cement stabilization}

According to the design requirement of cement content, thickness of pavement and compaction, width and length of construction to be applied, the program will calculate automatically the total amount of cement to be applied, the distance of the cement bags to be laid in both directions which is an easy way for the construction in quality control and application in cement stabilization works.

\subsection{Asphalt concrete test}

\subsubsection{Absorption by aggregate test}

The absorption by aggregate test calculation method followed is the ASTM D 4469-97.

\subsubsection{Bitumen content prediction}

Bitumen content in the asphalt concrete is predicted as per MS-2, the exact value shall be determined by the Marshall test.

\subsubsection{Bitumen extraction test}

The test method of ASTM D 2172-95 and AASHTO T 164-97 are adopted to determine the bitumen content in the asphalt concrete.

2.4.4 Maximum theory density 
Test method of AASHTO T 209-94 and ASTM D2041-095 are used under the test temperature of $25^{\circ} \mathrm{C}$. The program provide calculation as per BS589: Part 31983 and MS-2 of America bitumen association to determine the Maximum Theory Density of asphalt concrete, the former includes calculation of air voids in the mixture, voids in the mineral aggregate and voids filled with binder.

\subsubsection{Bulk density}

Test method as per AASHTO T166-93 and T275-91 are made in the program. The bulk specific gravity of compacted bituminous mixture using SSD specimen and Bulk specific gravity of compacted bituminous mixtures using paraffin-coated specimens can be calculated accordingly.

\subsubsection{Marshall test}

AASHTO T166-93 is used to calculate the bulk density of specimen, and it will calculate water absorption automatically, if water absorption is greater than $2 \%$, the AASHTO T275 by using paraffin-coated specimen shall be used.The program use AASHTO T269-97 method to calculate air voids and voids asphalt concrete, using MS-2 method to calculate voids in mineral aggregate and voids filled with asphalt, using AASHTO T245-97 method to calculate the Marshall stability of asphalt concrete specimen. When the volume of specimen is changed under $200-625 \mathrm{~cm} 3$, the program will automatically modify the Marshall stability and output the corrected stability value.

\subsubsection{Immersion test}

This is test method to review of strength loss after asphalt concrete immersion in water. There are two test method: one is using AASHTO T 165-97 or ASTM D1075-94 test method and another one is using method as per MS-2. The former one specified that the height and the diameter of the specimen shall be same, and the difference between them shall be under $\pm 2.5 \%$, in addition the void ratio shall be controlled under $6 \%$, this methods is also called unconfined single axial compressive test, the latter is using standard Marshall Test specimen.

\subsubsection{Texture depth}

The texture depth of asphalt concrete surface is determined as per standard of BS598: Part 3, 1985. This is important index to review of anti-slip behavior for the road especially for the asphalt concrete road.

\subsubsection{Compaction influence factors for asphalt concrete}

As per bitumen association document of MS-8, the program provides criteria of compaction for asphalts concrete and 6 influences factors for compaction of asphalt concrete.

\subsubsection{Adjusting of asphalt concrete mix proportion}

As per bitumen association document of MS-2, the program provides method for adjusting asphalt concrete.

\subsubsection{Three aggregate density of asphalt mixture}

The program provides test calculation for three aggregate densities of asphalt concrete mixture so that the correction of the basic test can be checked.

\subsubsection{Others}

The program provides conversion calculation between bitumen content and bitumen over aggregate ratio which can be used for production control over the asphalt concrete mixing plant. The program also provides the actual air void ratio calculation under different compaction and designed air void ratio.

2.5 Selection of parameters for surface dressing

2.5.1 Bitumen and chipping spreading rate calculation

As per document the Program provides both of bitumen spray rate and chipping spreading rate calculation so that user can select construction parameter quickly and easily. The program can be used for calculate the mean minimum size of 
chipping.

\subsubsection{Chipping spreading test}

As per BS 598: PART 3: 1985, the program provides the chipping spreading test calculation.

2.5.3 Grading test for surface dressing

According to test data, the program provides envelop curve of the grading for the surface dressing material, it can be used for checking surface dressing material in size of $10 \mathrm{~mm}$ and $20 \mathrm{~mm}$, and checking them within the specified limit or not so that the construction quality control shall be applied.

\subsection{Other functions}

The computer program can be used for Unit conversion for 23 different kinds of Units. The computer program describes some of the requirements for sampling. The technical terminology relates to 8 no. of density and relative density, 21 items relates to road base material and 62 items relates to bitumen and non-bitumen material can be found in the program.

When the minimum weight of sample is known and minimum readable figure is known for the balance, the program can be used for checking the measuring accuracy meets requirement or not so that suitable measuring balance can be selected or suitable minimum weight of sample can be adjusted. The program provides 38 kinds of sieve size both in American unit and standard unit, and also provides the allowable dimension error for each sieve size. The program provides the basic idea, technical specification, problem to be solved, safety notice, service information, radiation calculation and so on when nuclear gauge is used for the compaction density test.

\section{Conclusions}

(1) The Computer Aided Test Analysis for Civil Engineering (CATACE) can be used for construction quality control in testing and controlling in Civil Engineering Works.

(2) The CATACE is suitable for the project applying international standard, it can be used for quick analysis for the test data; it can be used for comparative study from the test between Chinese and overseas.

(3) The program is written in English, it provide the assistance information for the understanding of the Program. It is especially suitable for those engineers who are working for Oversea Civil Works.

(4) The program have been have been successfully used in some oversea project for civil works.

\section{Conflicts of Interest}

The author declares no conflicts of interest regarding the publication of this paper.

\section{References}

[1] Overseas Road Note 3 A Guide to Surface Dressing in Tropical and Sub-tropical Countries, Transport and Road Research Laboratory Crowthorne Berkshire United Kingdom, 1982.

[2] Wu Z. (2016). Management of Design and Construction for Civil Works under EPC Content in One Oversea Wind Farm Project. World Construction, 5(2): 1-10.

[3] Zhou Q.S. and Wu Z. (2019). Technical Reviews for One Oversea Road Project under Design and Built Contract. Journal of Building Engineering Technology Research, 1(1): 41-46.

[4] Luo W., Wu Z. and Fang X.Q. (2004). Making of Cut-back Bitumen for One Oversea Road Project. Highway, (06): 134-137. 